\title{
DESIGN DA PÁGINA INTERATIVA NA PERSPECTIVA DA SEMIÓTICA SOCIAL
}

\author{
Vilson J. Leffa* \\ Gabriela Q. Marzari
}

Resumo: O uso dos computadores no ensino e aprendiragem de linguas, ao mesmo tempo em que pode tornar mais interessante o trabalho do professor, tem também exigido o dominio de novos conbecimentos nem sempre fáceis de serem adquiridos. O objetivo deste texto é refletir sobre a página digital como espaço de interação propicio à aprendizagem. Para isso, faz-se um retrospecto da página impressa e mostra-se que ela tem um peso muito grande sobre o desenvolvimento da página digital, o que leva à necessidade de se faz̧er uma distinção entre a página digital, essencialmente estática, e a página digital interativa, essencialmente dinâmica. Enquanto a página impressa e a digital têm leitores, que se posicionam externamente, a página interativa tem participantes, que se posicionam internamente, em imersão total. Acredita-se que a compreensão e a exploração dos recursos da página interativa podem tražer uma contribuição importante para um ensino de linguas mais eficiente.

Palavras-chave: Aprendizagem de línguas. Aprendizagem mediada por computador. Semiótica social.

\section{INTRODUÇÃO ${ }^{1}$}

Há um consenso entre os pesquisadores de que a expansão dos computadores e da internet trouxe para professores e alunos novas maneiras de ensinar e aprender línguas (AHMAD et al., 1985; HIGGINS, 1988; KENNING; KENNING, 1990; WARSCHAUER, 1996; BAX, 2003; CHAPELLE, 2005; LEFFA, 2006; PAIVA, 2008). O objetivo deste trabalho é refletir sobre as possibilidades pedagógicas propiciadas pela tecnologia digital na elaboração de material didático, com base nos princípios teóricos da Semiótica Social (HALLIDAY, 1994; KRESS; VAN LEEUWEN, 2006; LEMKE, 2002). Procura-se, especificamente, avaliar quais são as contribuições, em termos teóricos e práticos, que essa perspectiva teórica pode trazer para o design da página interativa como material didático.

\footnotetext{
* Professor da Universidade Católica de Pelotas. Pesquisador do CNPq. PhD em Linguística Aplicada. E- mail: leffav@gmail.com.

** Professora do Centro Universitário Franciscano. Doutoranda em Linguística Aplicada. E-mail: gabrielamarzari@gmail.com.

1 Agradecemos aos pareceristas anônimos pelas observações feitas, lembrando que os erros remanescentes são de nossa responsabilidade.
} 
Partimos do pressuposto de que o conceito de página é um elemento relevante para a educação, não só por delimitar, guardar e expor um determinado conteúdo, mas também pela sua potencialidade em apoiar a ação pedagógica do professor. Vamos mostrar como esse conceito evolui historicamente em seus diferentes suportes, desde a página impressa, fundamentalmente estática, passando pela página digital, teoricamente dinâmica, mas na prática ainda presa à imobilidade do texto impresso, até chegar ao que definimos como página interativa, capaz de responder ao gesto do leitor, agora promovido à categoria de participante.

Para mostrar essa evolução, dividimos o texto em três partes. $\mathrm{Na}$ primeira (seção 2), analisamos as diferenças entre a página impressa e a página digital e mostramos que, embora teoricamente variem muito em termos de affordance, essa variação não se reflete na prática, que persistentemente permanece a mesma. Na segunda parte (seção 3), enfocamos a evolução que acontece da página digital à página interativa, tendo como exemplo os games. Finalmente, na terceira parte (seção 4), procuramos mostrar as promessas e as limitações da página interativa como ferramenta de apoio didático, destacando o papel do professor e do aluno, como agentes que interagem por meio do conteúdo a ser desenvolvido.

\section{DA PÁGINA IMPRESSA À PÁGINA DIGITAL}

Uma diferença entre a página impressa no papel e a página digital, apresentada na tela do computador, que não tem sido devidamente considerada na produção de material didático, é que, ao contrário da página impressa, a página digital é sensível à ação do usuário, quer seja pelo toque direto na tela, pelo movimento dos dedos sobre um painel de navegação, por um clique do mouse e até por gestos capturados pela câmera e interpretados por um algoritmo interno da máquina. Enquanto a página impressa é essencialmente estática e rigorosamente inerte a qualquer ação física do leitor, a página digital tem uma potencialidade dinâmica e é capaz de responder ao gesto do usuário com outros gestos, usando não apenas texto verbal e imagem, mas também outros recursos, inviáveis na página impressa, como áudio e vídeo. A página digital é apenas a ponta visível de um processador eletrônico, que ela oculta atrás 
de si e que tem o poder de proporcionar dois recursos relevantes na aprendizagem: interatividade e interação. $\mathrm{O}$ recurso da interatividade pode permitir, por exemplo, que a resposta dada pelo aluno seja comparada com as informações de um banco de dados, armazenado no próprio computador ou em outra máquina da rede, e que um feedback seja automaticamente fornecido. Já o recurso da interação pode colocar o aluno em contato com outro aluno ou professor, para a troca de ideias online, em modo síncrono ou assíncrono.

Os recursos de áudio, vídeo, interatividade e interação são as affordances que caracterizam a página digital, propiciando, de um lado, benefícios que não existem na página impressa, mas exigindo, de outro lado, um investimento inicial em termos de aprendizagem por parte do professor, provavelmente maior do que por parte do aluno, o que acaba produzindo um impasse na sua utilização. Quer seja levado por uma real falta de tempo ou mesmo por neofobia, caracterizada pela resistência ferrenha a tudo que é novo, o professor pode sumariamente desqualificar o uso dos recursos digitais como um modismo passageiro. $\mathrm{Na}$ medida, porém, em que a página digital impõe-se pelo baixo custo financeiro e pela facilidade de socialização via blogs, e-mails e redes sociais, seu uso deixa de ser uma opção para o professor, tornando-se inevitável. O que poderia, então, ser usado voluntariamente pelas qualidades intrínsecas que apresenta acaba sendo usado por imposição de uma sociedade cada vez mais virtualizada.

Um dos perigos dessa postura digital imposta ao profissional da educação é que ele possa trazer para o mundo cibernético a mesma maneira de trabalhar, ensinar e principalmente de pensar que caracterizava o mundo pré-cibernético. Concorre para isso a possível percepção do computador como uma máquina de escrever sofisticada, de modo a ver no texto verbal transposto para a tela do computador uma mera duplicação do texto impresso no papel, às vezes apoiada pelas próprias ferramentas usadas pelo professor. Os recursos dos processadores de texto (Microsoft Word e BrOffice, entre outros) parecem estimular essa duplicação ao oferecerem a possibilidade de salvar o texto digitado como página da $W e b$, dando ao professor a ilusão de que se tornou um professor digital. O resultado, no entanto, é a mera transposição da página impressa para a página digital, presa ainda às características do mundo pré-cibernético, ou seja, uma página muda, 
quando poderia ser sonora; estática, quando poderia ser dinâmica; e impassível, quando poderia ser responsiva aos gestos do aluno. "É possível usar novas tecnologias para simplesmente replicar antigas práticas de letramento, conforme vemos ad infinitum em salas de aula contemporâneas." (KNOBEL; LANKSHEAR, 2007, p. 7). O computador sofisticado que gerencia essa página digital, com capacidade de realizar milhões de operações por segundo, é transformado num mero virador eletrônico de páginas. A ideia de Piérre Lévy de "um texto móvel, caleidoscópico, que apresenta suas facetas, gira, dobra-se e desdobra-se à vontade frente ao leitor" (LÉVY, 1999, p. 56) tem mais a ver com uma possibilidade não concretizada do que uma realidade.

Vários fatores parecem ter contribuído para essa permanência. A tradição da página impressa em formato retrato, mais alta do que larga, parece ter um peso muito grande, tratando-se de uma preferência histórica que vem dos pergaminhos e códices da Antiguidade e da Idade Média, posteriormente adotada pelo livro impresso no século XVI, e que permanece até hoje. Os cadernos usados pelos alunos na escola, as folhas em branco, A4 ou tamanho ofício, usadas para impressão, as revistas, os jornais, são todos apresentados nesse formato, com as raras exceções que confirmam a regra. É interessante ressaltar que entre as exceções estão os cadernos de desenho, encontrados normalmente no formato paisagem; preferimos escrever no formato retrato e desenhar no formato paisagem. A linha de texto no formato paisagem ficaria muito extensa e o leitor poderia se perder ao tentar passar para a linha seguinte. Daí a necessidade de dividir a página impressa em colunas, principalmente nas revistas e mais ainda nos jornais. Note-se que esse recurso é mais usado para textos do que para ilustrações; basta uma olhada nas páginas impressas para perceber que as ilustrações tipicamente abrangem mais de uma coluna. Ainda que muitos autores (ISER, 1974; ECO, 1976; GOODMAN, 1991; SMITH, 2003; entre outros) apregoem a não linearidade da leitura proficiente, o uso de colunas estreitas, ao privilegiar a verticalidade na impressão dos textos, contradiz essa perspectiva panorâmica da leitura. A escrita é vertical; o desenho é horizontal.

O formato paisagem popularizou-se com o advento da televisão, que foi feita para mostrar imagem e não texto verbal, inicialmente em $4 \times 3$ e depois evoluindo para o formato $16 \times 9$, que pode ser considerado o padrão atual. A divisão entre texto verbal e imagem em movimento foi 
feita pacificamente, ficando aquele com o suporte impresso, em formato retrato, e esta, com o suporte televisivo, em formato paisagem. Essa divisão de trabalho permaneceu pacífica até o advento do computador, quando a tela passou a ser usada não só para apresentar imagens, mas também, e principalmente, para mostrar e produzir textos escritos. A introdução de telas giratórias, possibilitando a escolha entre retrato e paisagem, foi experimentada por alguns fabricantes, mas não obteve sucesso; a combinação de um teclado físico horizontal com uma tela vertical parece ter desagradado aos usuários. Foi só com a introdução dos tablets, em que o teclado físico desaparece para dar lugar ao teclado virtual, que finalmente parece ter ocorrido a fusão do texto com a imagem em movimento, permitindo que o usuário gire o tablet como desejar, lendo um texto na posição vertical e assistindo a um vídeo na posição horizontal.

Enquanto a página impressa em papel caracteriza-se pela solidez da composição gráfica, evoluindo lentamente com o tempo, a página digital caracteriza-se pela mobilidade, indo e voltando rapidamente no tempo, mas rigorosamente não se afastando muito da página impressa. Não é exagero afirmar que a página digital é uma herança da página impressa. Mantém de sua antepassada o gosto pela retangularidade bidimensional do papel, tipicamente com a mesma composição gráfica na distribuição de texto verbal e ilustrações, ainda que ocasionalmente quebrando a harmonia do layout com janelas animadas para destacar chamadas de publicidade. Às vezes recua historicamente para períodos anteriores à página impressa. É o caso, por exemplo, da preferência generalizada pelo recurso do scroll, que se caracteriza pelos longos rolamentos verticais na tela do monitor, o que lembra os manuscritos em rolo, usados na Idade Média e acionados por manivelas, ou ainda os rolos de papiro do Antigo Egito. Recupera-se uma prática perdida no tempo para manter o mesmo princípio da rolagem do texto, substituindo-se as manivelas pelo botão do mouse. Ao contrário da página impressa, que fragmenta o texto nas folhas do livro, que são viradas pelo leitor, a página digital forma um elemento único, sem divisões; ela não é virada, mas rolada pelo leitor. O obstáculo do formato paisagem, que caracteriza a tela do monitor, é contornado pelo recurso da rolagem em sentido vertical, que acaba simulando o formato retrato, característico da página impressa. 


\section{DA PÁGINA DIGITAL À PÁGINA INTERATIVA}

A introdução do computador trouxe, para o mundo do leitor, a tela digital, que é um espaço dinâmico alimentado por um complexo sistema operacional que gerencia e controla cada um dos inúmeros e minúsculos pontos luminosos ali exibidos. Por sua extrema capacidade de renovação, a tela digital pode agir como um camaleão eletrônico, facilmente assumindo os mais diversos formatos, seja como uma simples página de livro, o quadro de um artista famoso, ou algo mais complexo como um vídeo ou um game, simulando as mais diferentes situações. Daí a dificuldade de se escolher um termo adequado para definir esse espaço, tanto pela sua diversidade de uso, como pela especificidade que se possa às vezes desejar para um objetivo mais peculiar. $O$ uso da expressão "página digital", por exemplo, é perfeitamente adequado quando se usa a tela para ler ou escrever um texto, mas será menos apropriado para a exibição de um vídeo. Além de "página" e o genérico "tela", existem também inúmeros sinônimos, incluindo, por exemplo, termos como monitor, display, quadro, campo, janela (popularizada pela Microsoft com o sistema denominado Windows), entre outros. Para descrever o problema que estamos tratando aqui, precisamos, no entanto, de um termo que defina a relação de interatividade entre o usuário e a tela e que caracterize a tela, não apenas como mídia, mas como coagente da ação, junto com o usuário, muito além do conceito tradicional de "página impressa" e mesmo de "página digital". O termo "Janela" não nos parece adequado porque dá a ideia de observação (o usuário vendo a ação através da janela) e não diretamente envolvido com o que acontece. Na falta de um termo melhor, estamos propondo "página interativa", entendido como um espaço digital onde um evento se desenvolve, desencadeado e sustentado pela ação do usuário. Trata-se tipicamente de um evento de natureza aleatória, imprevisível em seus desdobramentos, tanto pelo autor que produziu a atividade, como pelo usuário que a executa; num game, por exemplo, o adversário pode surpreender o jogador a qualquer momento e de qualquer lugar da tela, a partir de sementes randômicas plantadas no sistema.

Além dos conceitos específicos de página digital e página interativa, precisamos também de um termo que englobe qualquer artefato cultural tipicamente usado para produzir sentido, como texto, 
imagem, música, filme, hipertexto, etc. $\mathrm{Na}$ falta de um termo mais adequado usamos aqui, para esse conceito mais abrangente, o termo artefato midiático. Os três tipos de páginas descritos até aqui - impressa, digital e interativa - encaixam-se nesse conceito.

Vejamos brevemente como o conceito de página interativa contrapõe-se à ideia tradicional de página, não só a impressa, mas também a digital. A página impressa e a digital são produzidas para serem lidas. A progressão da leitura, tanto num caso como no outro, é marcada pela dimensão espacial, quer virando as páginas impressas em papel, quer rolando o texto na tela do monitor. É impossível progredir na leitura sem esses movimentos de virada ou de rolagem (scroll), que vão progressivamente substituindo os segmentos do texto. Já na página interativa, a progressão normalmente não se dá pela dimensão espacial, com a substituição de uma página por outra, mas pela dimensão temporal, em que a mesma tela transforma-se pela ação do usuário. A página não vira nem rola para outras páginas; transforma-se apenas, ocupando sempre o mesmo espaço. A diferença entre a página digital e a página interativa, ainda que ambas possuam o mesmo suporte digital, é muito maior do que a diferença entre a página digital e a página impressa, apresentadas em suportes diferentes. Não é o suporte, digital ou impresso em papel, que faz a diferença, mas a expectativa de ação, implícita na elaboração da página. A página interativa não foi produzida para ser apenas lida, mas para ser ativamente explorada pelo leitor, nesse caso, promovido à categoria de participante. A tela que está na sua frente deixa de ser uma página estática, como acontece na leitura do texto impresso. Embora não se defenda aqui que a leitura tradicional seja um processo passivo, em que o leitor permanece como um mero receptor de informações, ainda assim, por mais que se reconheça nela um processo responsivo no qual o leitor mobiliza seu conhecimento prévio para construir sentidos, é preciso reconhecer que na leitura tradicional não há, rigorosamente falando, um processo de interação que implique a transformação dos agentes (LEFFA, 2011; SWAIN, 2006). Na página digital, o leitor pode até mexer um pouco no texto, aumentando, por exemplo, o tamanho da letra, como pode também, na página impressa, aproximá-la mais de uma fonte de luz para poder enxergar melhor o que está escrito, mas o texto permanece inerte na sua frente; é apenas o leitor que se transforma e sempre do lado de fora da página. 
Como participante, o sujeito não apenas mexe na configuração da tela interativa, mas, principalmente, insere-se no contexto da página, podendo assumir diferentes papéis. Num game de ação, por exemplo, ele será jogador, e vai interagir diretamente com outros jogadores, que vão reagir a cada gesto, defendendo-se ou atacando. Tipicamente, não há movimentação para outras páginas, quer por rolagem ou por virada de página. A página interativa é um espaço em que as coisas acontecem no mesmo lugar, embora às vezes o participante possa evoluir para diferentes estágios: a paisagem da fazenda, por exemplo, onde os legumes foram plantados e colhidos, pode ser substituída pela paisagem da feira, onde os produtos serão negociados. Muitos dos games clássicos (Pac-Man, Space Invaders, Tetris, entre outros) seguem as regras aristotélicas do teatro, obedecendo às três unidades de espaço, ação e tempo, como se a tela do computador fosse um palco, ou uma arena da antiguidade, para a representação de uma peça. À semelhança do que já acontecia no Coliseu de Roma, em que a plateia podia decidir o destino do gladiador, levantando ou baixando o polegar, a página interativa, como é descrita aqui, não só espera, mas depende da intervenção do espectador. Diferentemente do Coliseu, no entanto, o sujeito nem sempre está na arquibancada, comandando o jogo do lado de fora, junto com os espectadores; geralmente está do lado de dentro, no meio da arena, junto com outros atores.

Usando como exemplo um dos mais populares games de todos os tempos, Space Invaders, criado por Toshihiro Nishikado em 1978, vejamos como acontece esse envolvimento do usuário na ação do jogo. O game, baseado no clássico de ficção científica Guerra dos Mundos, segundo o autor, trata da invasão da Terra por alienígenas, e o usuário, transformado em protagonista, tem por missão defender o planeta, usando um disparador de mísseis que se desloca sobre uma plataforma na base da tela. Descendo do céu, chegam blocos de alienígenas em formação fechada, protegidos por armas que disparam aleatoriamente, tentando atingir o protagonista e romper as casamatas que o protegem. A ação é constante e a duração do jogo depende da habilidade do jogador: será breve se ele não souber se proteger e atacar; será mais longa se ele conseguir usar as estratégias adequadas. O usuário-personagemprotagonista não assiste aos acontecimentos, mas participa deles, sofrendo a consequência de suas ações. A batalha, uma vez iniciada, não 
tem pausa e prossegue incansavelmente até a morte do herói, lembrando as tragédias gregas, em que o protagonista acaba sempre vencido, como um joguete nas mãos dos deuses. Não há uma sobrevivência definitiva; por mais que o herói se esforce e se empenhe, chegará sempre o momento em que o jogo termina para ele (Game Over), e sempre com a vitória da máquina. Num game, como na vida, ninguém vive para sempre. O que conta são os pontos conseguidos enquanto estiver vivo, podendo, com muita sorte e esforço, ter seu nome temporariamente imortalizado no Hall da Fama, uma espécie de vida após a morte no mundo dos games.

\section{A PÁGINA INTERATIVA NO ENSINO E NA APRENDIZAGEM DE LÍNGUAS}

A página interativa só é possível no suporte digital, pela affordance que esse suporte propicia, usando algoritmos da máquina para simular diferentes ambientes do mundo real ou imaginado, e povoando a tela com agentes que interagem não só entre si, dentro da tela, mas também com o usuário, respondendo ao seu gesto, ou mesmo iniciando a ação e obrigando-o a agir, para se defender ou contra-atacar. $\mathrm{O}$ que acontece numa sessão interativa não fica restrito à mente do usuário, como na leitura, mas distribui-se entre o sujeito e o artefato midiático a sua frente, que, pela sua capacidade de reagir e agir, é alçado de mero recurso mediacional para agente, agindo de igual para igual com o usuário (LEFFA, 2011), muitas vezes a ponto de vencê-lo, como se vê em muitos games.

O que propomos fazer aqui é investigar a possibilidade de trazer a interatividade e agência dos games para a aprendizagem, com ênfase no ensino de línguas, tentando mostrar de que modo as affordances propiciadas pelos recursos da informática podem ser exploradas para uma produção mais eficaz de sentido, em comparação com a página impressa ou digital, como a definimos aqui. A página interativa vai muito além do sistema semiótico meramente linguístico, com a possibilidade de aproximar-se mais do mundo real do aluno em sua multiplicidade semiótica (SALEN; ZIMMERMAN, 2004), em que sons, imagens e movimentos, como significantes, combinam-se para tornar mais precisa a determinação dos significados. Lemke, por exemplo, afirma que " $[\mathrm{t}]$ oda semiose é multimodal"'(2002, p. 302), dando a entender que os sistemas 
semióticos podem ser integrados, enriquecendo o processo de significação e produzindo uma experiência comunicativa mais intensa, envolvente e clara para o sujeito, em comparação com o que acontece com o uso de um único sistema semiótico, apenas linguístico ou apenas imagético, que pode limitar e mesmo atrofiar a comunicação.

A construção de sentido pelo aluno que interage com o espaço delimitado pela página interativa, na perspectiva da semiótica social, é determinada pelas funções que fundamentalmente constituem esse artefato midiático: (1) representar um mundo possível; (2) interagir com o sujeito; (3) auto-organizar-se como artefato. A terminologia usada para definir essas funções varia de um autor para outro, variação essa que entendemos motivada pela diferença do objeto investigado: enquanto Halliday (1994) analisava o sistema linguístico, Kress e van Leeuwen (2006) atinham-se à gramática visual e Lemke (2002) ancorava-se no fenômeno da hipermodalidade. Embora os objetos analisados sejam diferentes, entendemos que as metafunções são suficientemente amplas e semelhantes para singularizá-las nos três processos fundamentais de produção de sentido com artefato midiático, sejam eles um objeto verbal, imagético ou hipertextual. O Quadro 1 resume a terminologia usada pelos autores e os termos propostos para este trabalho.

\section{Quadro 1 - Metafunções com a terminologia proposta neste trabalho}

\begin{tabular}{|l|l|l|l|}
\hline HALLIDAY & $\begin{array}{l}\text { KRESS \& VAN } \\
\text { LEEUWEN }\end{array}$ & LEMKE & $\begin{array}{l}\text { TERMINOLOGIA } \\
\text { PROPOSTA }\end{array}$ \\
\hline Ideacional & Representacional & Apresentacional & Representacional \\
\hline Interpessoal & Interativa & Orientacional & Interacional \\
\hline Textual & Composicional & Organizacional & Composicional \\
\hline
\end{tabular}

\section{Fonte: Elaboração própria.}

Optamos por usar neste trabalho os termos representacional, interacional e composicional, mas sem a preocupação de cobrir exatamente os mesmos conceitos propostos por Halliday, Kress \& van Leeuwen e Lemke, ainda que acreditemos serem bastante próximos. Apesar dessa proximidade, sentimos, no entanto, a necessidade de delimitar operacionalmente esses termos. Partimos basicamente do pressuposto de 
que os artefatos midiáticos oferecem possibilidades de conexões que podem ser construídas entre o artefato e o mundo que ele representa, entre o artefato e o sujeito que com ele interage e entre elementos que compõem o próprio artefato. Por princípio, construir sentido é descobrir essas conexões. Assim, tendo por objeto de estudo a página interativa, vemos que ela oferece ao aluno três possibilidades de construção de sentido, na medida em que cada uma das metafunções é concretizada; definiremos esse momento de concretização como instanciação da metafunção. A metafunção representacional é instanciada no momento em que o sujeito constrói sentido, fazendo a conexão entre elementos do artefato midiático e elementos do mundo, mas sem envolvimento direto do sujeito, que exerce um papel de observador do suporte. Já a metafunção interacional instancia-se quando o sujeito se envolve com o artefato, fazendo uma conexão direta com ele; deixa de ser observador para ser ator. Finalmente, na metafunção composicional, o sentido é construído pela conexão de elementos que estão dentro do artefato, sem envolver o mundo representado ou o sujeito. Essas metafunções são separadas aqui apenas por questões de exposição didática; na prática comunicativa do dia a dia, elas são instanciadas simultaneamente. $\mathrm{Na}$ página interativa, como veremos mais adiante, não seria nem possível construir sentido sem essa simultaneidade.

\subsection{Metafunção representacional}

Uma questão que se coloca de imediato, ao pensar a função representacional no ensino de línguas em uma página interativa, é que mundo o conteúdo dessa página deve representar. Existem várias possibilidades aqui, desde uma ênfase na forma, com foco no sistema da língua, até uma ênfase no conteúdo, com foco no contexto e uso, incluindo aspectos pragmáticos.

A página interativa associa-se a uma tradição de ensino de línguas mediada por computador, definida em língua inglesa como CALL (Computer-Assisted Language Learning), inicialmente caracterizada por uma ênfase em exercícios estruturais para a automatização dos padrões básicos da língua (pattern drills). Nessa visão, a página interativa representaria para o aluno um mundo linguístico estruturado em torno do léxico e da sintaxe. Apesar das críticas contra a ênfase no sistema e no 
uso de exercícios (WONG; VANPATTEN, 2003), muitos autores têm defendido a necessidade de uma instrução explícita com foco na forma (LONG; ROBINSON, 1998; DOUGHTY; WILLIAMS, 1998; VIDAL, 2007; FOTOS; NASSAJI, 2007). A ênfase no léxico e mesmo na sintaxe pode também harmonizar-se com uma ênfase no significado, com o uso de exercícios que partam do significado para a forma, como se percebe na Hipótese do Processamento do Input, proposta por VanPatten (1995) e demonstrada em Wong e VanPatten (2003). A ideia, neste caso, é de que é possível adquirir inconscientemente a forma, executando uma atividade com a atenção no significado.

A página interativa pode dar conta dos dois aspectos, tanto com ênfase na forma, falada ou escrita, como no conteúdo, envolvendo não só aspectos básicos de uma semântica lexical (sinonímia, antonímia, hiperonímia, uso da cor nas imagens, etc.), mas também uma possível semântica sintática (ordem adequada das palavras, pontos de segmentação na frase, relação entre os elementos de uma figura, sequência de tomadas numa cena de vídeo, etc.). Veja-se, por exemplo, a ambiguidade da frase "O policial viu a mulher de binóculo", em que, sem informação do contexto, não é possível saber quem estava de binóculo; já na frase "O policial viu a mulher de vestido vermelho", considerando um contexto tradicional, a ambiguidade desaparece. Em um vídeo, as mesmas tomadas, montadas em sequências diferentes, podem mudar o significado, transformando, por exemplo, causa em efeito e vice-versa.

A língua, sons e imagens não apenas se materializam num sistema - lexical, sintático ou semântico - mas também se constituem num instrumento de ação, sendo capaz de representar o mundo em dois aspectos fundamentais, narrativo e conceitual. No aspecto narrativo, mostra um evento ou sequência de eventos em que pessoas agem com outras pessoas e com objetos, provocando mudanças. Relações de poder, estereótipos e preconceitos podem ser não apenas retratados, mas culturalmente induzidos, criando-se associações que naturalmente não existem: a esposa japonesa recebendo o marido de joelhos na porta, o brasileiro como solidário, a língua popular como código empobrecido.

No aspecto conceitual, vemos como objetos do mundo representados no texto escrito, na imagem ou no vídeo - podem ser segmentados, realocados, classificados e até usados como símbolos para outros objetos. Mostra-se não só o mundo real, mas também o mundo 
que imaginamos e que queremos, para nós e para os outros. O mundo representado ao qual estamos expostos pode ser apenas o fragmento de um mundo possível, resultado de uma escolha individual ou institucional, atendendo a interesses que podem ou não estar de acordo com os nossos. O fato de ser uma representação do mundo, que pode ser alterada e manipulada pelo autor, o texto verbal, a imagem ou o vídeo sugere a necessidade de uma postura crítica por parte do usuário. Um comercial de TV, por exemplo, pode mostrar que quem usa ou adere a um determinado produto - seja pizza, sindicato, automóvel ou partido político - é sempre mais feliz e elegante do que quem não tem ou não usa esse produto. A associação entre pizza e elegância não é natural, mas induzida. $\mathrm{O}$ comercial tem um objetivo claro, que não é representar o mundo como ele realmente é, mas vender a pizza. Quando usamos a língua, a imagem ou um vídeo, temos um objetivo em mente. $\mathrm{Na}$ perspectiva da semiótica social, não se representa o mundo para representar o mundo; representa-se o mundo para agir sobre os outros.

A página interativa, pelo suporte da multimodalidade que a instrumentaliza, pode representar o mundo com mais eficiência por meio de diversos instrumentos, muito além do sistema semiótico da língua escrita. Mesmo dentro do sistema linguístico, a página interativa já possui vários recursos que podem dar conta de inúmeros aspectos que são relevantes na construção de sentido, incluindo, por exemplo, pronúncia, entonação, ritmo da fala, pausas, diferentes sotaques, etc. $\mathrm{O}$ uso da imagem e do movimento amplia seu poder de ação, representando para o usuário um mundo que simula muito bem o mundo real, mas que normalmente é muito diferente dele. O que narra pode não ter acontecido, e os conceitos apresentados podem também não corresponder à realidade. Como nada acontece por acaso, incluindo sempre uma intenção, assumida ou não, o mundo representado na multimodalidade pode agir tanto em benefício como em prejuízo do próprio usuário; talvez com mais perigo, por ter um poder de fogo maior e pela ingenuidade do observador que muitas vezes não vê na imagem e no áudio o poder de persuasão que lhes é inerente. Daí, segundo a semiótica social, a necessidade de criar uma postura crítica diante dessa nova maneira de representar o mundo (OLIVEIRA, 2006; KRESS; VAN LEEUWEN, 2006; entre outros). 


\subsection{Metafunção interacional}

A metafunção representacional instancia-se dentro dos limites do próprio artefato midiático; relaciona pessoas, eventos e objetos de um mundo possível, mas apenas como representação; não há conexão com os sujeitos que estão do outro lado, no mundo externo. Já a metafunção interacional instancia-se justamente quando há essa conexão entre os elementos do artefato midiático e o sujeito que lê um texto verbal observa uma imagem ou assiste a um filme.

É desse encontro que se inicia uma nova maneira de produzir sentido, com a redefinição dos papéis de um e de outro lado. Na página interativa, o sujeito deixa de ser leitor ou espectador para se transformar em agente, interferindo e provocando mudanças no que está a sua frente. A página interativa, por outro lado, deixa também de ser o espelho de um mundo possível, para tornar-se, ela própria, um agente de fato, interagindo com o usuário. Há quatro possibilidades nessa relação, que podemos definir como oferta e demanda, distância, perspectiva e modalidade, seguindo a terminologia de Kress e van Leeuween (2006). Vejamos como se instancia cada um desses casos, considerando a página interativa.

Começando pela oferta e demanda, podemos argumentar que a página interativa pode apresentar uma relação de subordinação ou de superioridade com o usuário, quer oferecendo bens ou serviços e colocando-se a seu dispor, quer impondo tarefas, cobrando e exigindo sua execução pelo usuário. Considerando que a página interativa é fundamentalmente um terminal de computador, podemos dizer que temos no primeiro caso o que tem sido tradicionalmente definido como um computador burro a serviço de um aluno inteligente, em oposição ao que acontece no segundo caso, um computador supostamente inteligente comandando um aluno burro (PAPERT, 1985). É a mesma ideia defendida por Higgins e Johns (1984), quando argumentam que o computador pode ser usado como tutor, ensinando o aluno, ou como ferramenta, servindo ao aluno como escravo. Nos termos da Semiótica Social, há, entre o usuário e a página interativa, uma relação de poder que balança de um lado para o outro: na oferta, o controle está nas mãos do usuário, exercendo um papel de sujeito em relação ao objeto; já na demanda, os papéis se invertem e o usuário se transforma em objeto. $\mathrm{O}$ 
computador é escravo do usuário, por exemplo, quando disponibiliza as máquinas de busca, corrige automaticamente o texto digitado, alinha os parágrafos, etc. É tutor quando apresenta tarefas para o aluno, faz perguntas, avalia respostas, impõe regras, ensina, etc. A possibilidade de agência da página interativa favorece a alternância de poder com o usuário, que conduz a ação em determinados momentos, mas é também conduzido em outros. $\mathrm{O}$ aluno que se inicia no estudo da língua deixa-se mais facilmente conduzir pelo computador, aceitando-o como tutor. Já o aluno avançado prefere conduzi-lo, usando-o como um instrumento para atingir os objetivos que tem em mente.

A distância social que existe entre as pessoas no mundo real pode também existir na relação entre o usuário e a página interativa. Tradicionalmente essa distância tem sido imposta pelo autor do artefato midiático que pode optar, por exemplo, desde um plano geral (batalha histórica, estádio lotado, desfile de uma escola de samba, etc.) até o closeup de um detalhe (rosto do soldado ferido, alegria na face do torcedor, enfeite no chapéu do porta-estandarte, etc.). $\mathrm{Na}$ página interativa, as fronteiras sociais que demarcam o espaço entre o sujeito e o objeto são mais flexíveis, por iniciativa do próprio usuário, que pode aproximar ou afastar o objeto com o qual deseja interagir. Em muitos games, por exemplo, é possível ampliar detalhes ou ter uma visão geral do campo adversário durante o jogo. O que era prerrogativa do autor passa para o controle do usuário/jogador, com tendência a aumentar na medida em que novas tecnologias são introduzidas; o uso do recurso da terceira dimensão, por exemplo, oferece não apenas uma visão em profundidade, mas também em proximidade, permitindo que as pessoas saltem da tela para se aproximarem do usuário.

O mesmo acontece em relação à perspectiva, em que o objeto de observação pode ser girado de várias maneiras pelo usuário, desde uma perspectiva horizontal (ângulo frontal, oblíquo e mesmo posterior) até uma perspectiva vertical (câmera alta, baixa ou ao nível do observador). O programa Google Earth (2011), por exemplo, permite que o usuário gire a imagem não só da esquerda para a direita, mas também de cima para baixo e vice-versa, alterando totalmente a perspectiva. Até a orientação norte/sul pode ser alterada, a ponto de colocar o hemisfério norte embaixo do hemisfério sul, invertendo uma relação culturalmente construída. 
Finalmente, em termos de modalidade, nunca foi tão fácil para o usuário transfigurar a realidade: um rosto pode ser facilmente rejuvenescido, um personagem pode ser metamorfoseado em um animal feroz, uma foto em um avatar gráfico, como uma figura, áudio ou vídeo pode ser renderizado de várias maneiras, produzindo vários efeitos, cada vez mais distantes do mundo natural. O impacto desses efeitos no estudo de línguas em áreas que valorizam a criatividade e a imaginação, como nos estudos literários, por exemplo, ainda está para ser avaliado.

\subsection{Metafunção composicional}

O sentido pode ser construído pela maneira como o artefato midiático representa o mundo (metafunção representacional), pela interação com o sujeito (metafunção interacional) e finalmente pela sua própria composição ou estrutura (metafunção composicional). Neste último aspecto, o sentido é construído pela relação entre os elementos que compõem o objeto, considerando o valor dado a um elemento em relação aos outros (ex.: o centro confere um valor maior do que a margem), a saliência (ex.: o elemento que está na frente chama mais a atenção) e a estruturação (maior ou menor coesão entre os elementos). $\mathrm{O}$ sentido construído a partir dessas relações está dentro do próprio objeto, não chegando a estabelecer relações com o mundo real nem com o sujeito que lê, observa ou interage com o artefato midiático.

O valor dado a um conteúdo pode depender da zona que ele ocupa dentro do artefato midiático, basicamente numa perspectiva bidimensional. Há três possibilidades de zoneamento: (1) centro versus margem; (2) esquerda versus direita; e (3) topo versus base.

A página interativa, como uma imagem, uma narrativa, e o próprio universo que construímos em nosso imaginário, compõe-se essencialmente de um centro e de uma periferia, organizados de tal modo que um reforça a existência do outro. O gramado onde se desenrola o jogo, o palco onde se representa a peça, o protagonista de uma história, todos adquirem sua importância em função do que está na periferia, seja a equipe técnica às margens do gramado, o pessoal dos bastidores no teatro ou os coadjuvantes da narrativa. No ensino de línguas, considerando o professor, o aluno e o conteúdo, o espaço

privilegiado é ocupado pelo conteúdo; é ele que representa o objetivo da 
aprendizagem. Não se vai à escola para dialogar com o professor ou fazer amizade com os colegas; não é esse o objetivo. Vai-se à escola para adquirir conhecimento. A importância do professor, dos colegas e da própria página interativa está no papel que eles têm como instrumentos para a aquisição do saber. $\mathrm{O}$ excesso de diálogo entre professor e aluno pode criar uma dependência, ao passo que um afastamento do professor do centro de ação, em favor do conteúdo, pode desenvolver a autonomia, como advoga Moore (2002, p. 9), na medida em que, nesse caso "é o aluno e não o professor quem determina os objetivos, as experiências de aprendizagem e as decisões de avaliação do programa de aprendizagem". Como o técnico em um jogo de futebol, o professor trabalha num espaço reservado à margem do gramado, ajudando no que for necessário, mas sem entrar em campo; é nessa marginalidade que o professor reforça a centralidade do conteúdo.

No modelo clássico de aprendizagem, temos o pressuposto de que devemos mobilizar o que já sabemos como um andaime para alcançar o que queremos aprender. Esse movimento do conhecido para o desconhecido, em nossa cultura, é normalmente feito da esquerda para a direita, não só na leitura de uma linha, mas também na mirada de uma imagem e mesmo na elaboração de um game, onde o personagem normalmente vence os obstáculos caminhando da esquerda para a direita. Na composição de uma página interativa com a presença do professor, a expectativa é de que o professor, que é conhecido, fique à esquerda do conteúdo, elemento desconhecido. Já em relação aos alunos, numa sala de aula simulada, a tendência é colocar o professor à direita, pressupondo que, para o aluno, o colega de aula é o mais conhecido.

O espaço superior é a zona do ideal, na proposta de Kress e van Leeuwen (2006). Na página interativa, é o objetivo a ser alcançado, representado pelo conteúdo. Ocupando a base do objeto, na zona da realidade, está o aluno. Portanto, a aprendizagem é um movimento não só da esquerda para a direita, mas também de baixo para cima. O aluno vai à escola para aprender, e aprender pressupõe a ideia de subir na vida, reforçado, mais uma vez, pela ideia do andaime.

A saliência viabiliza a terceira dimensão, substituindo os vetores bidimensionais esquerda/direita, topo/base e centro/margem pela visão de profundidade. $O$ conteúdo, em relação ao professor, vai para o primeiro plano, deixando o professor ao fundo, de certo modo, 
invertendo a sala de aula tradicional, com o professor normalmente à frente do quadro. Valoriza os recursos que podem ser usados para atrair a atenção do aluno, orientar sua aprendizagem e possivelmente garantir sua motivação. Na página interativa, por exemplo, o recurso da saliência pode ser usado para iluminar um objeto de modo a ser mais facilmente percebido; destacar um detalhe que deve ser visto como mais importante numa determinada hierarquia; despertar o interesse do aluno no próprio conteúdo.

Finalmente, a estruturação aponta para a maior ou menor conexão entre os elementos do artefato midiático, desde um enquadramento linear, altamente previsível, até um enquadramento aleatório, sem coesão explícita. No enquadramento linear a coesão é feita pelo autor, que mostra a conexão entre os elementos já construída, deixando-a explícita no próprio objeto; como não há necessidade de reestruturar os elementos, diz-se que a estruturação é fraca. Já no enquadramento aleatório, os elementos aparecem desconexos, havendo, portanto, necessidade de uma reestruturação. A página interativa, na medida em que se instancia de modo diferente para cada usuário, em cada sessão, sem uma sequência previsível de ações, parece enquadrar-se no segundo caso.

\section{CONCLUSÃO}

A página interativa, como a descrevemos aqui, difere da página impressa, e mesmo da página digital, por não ser um objeto estático, exposto ao olhar do leitor, tipicamente posicionado do lado externo. A página interativa é um evento que se instancia em reação a um gesto do participante, capturado por algum dispositivo de entrada (mouse, painel ou câmera), e que resulta em outro gesto, oriundo do objeto, dando algum tipo de resposta. As ações que constituem esse evento, descritas aqui separadamente, acontecem de modo simultâneo, provocando o desaparecimento das fronteiras entre o objeto, o usuário e o mundo, produzindo três grandes mutações com base em cada uma das metafunções: representacional, interacional e composicional.

Considerando a metafunção representacional, responsável pela conexão entre o objeto midiático e o mundo, vimos que, na página interativa, texto verbal, imagem, som e movimento revezam-se 
mutuamente, provocando mutações constantes. O que está escrito pode adquirir voz, o algarismo impresso transmuta-se em gráfico, o movimento de uma ação pode ser traduzido numa barra dinâmica, produzindo uma realidade aumentada: a integração de som, imagem e movimento cria um simulacro da realidade, com tal grau de definição que acaba se confundindo com ela, dissipando a fronteira entre a página interativa e as coisas do mundo que ela representa.

Considerando a metafunção composicional, a mutação envolve elementos que estão dentro do objeto. Podemos perceber que aquilo que é centro num momento pode ser deslocado para a periferia em outro, o que está em cima pode ir para baixo, o que está na frente pode ser movido para trás e vice-versa. Tudo depende da vontade do usuário. No Google Earth (2011), como vimos, o usuário pode aproximar e afastar a imagem, movimentá-la para a esquerda e para a direita, levantá-la e baixála e até girar o planeta de cima para baixo, invertendo o sentido, pondo o hemisfério norte ao pé da tela e o hemisfério sul no topo.

Finalmente, considerando a metafunção interacional, há uma imersão do sujeito no objeto, na medida em que o leitor transfigura-se em participante. Num game, por exemplo, ele não assiste ao jogo, mas participa como jogador, chutando a bola, derrubando o adversário ou sofrendo uma penalidade.

Todas essas mutações provocam fusões de diferentes níveis na instanciação da página interativa, produzindo uma formação extremamente híbrida, em que tudo se mistura: os elementos que compõem a página, a relação entre a página e o mundo que ela representa e a própria interação do sujeito com o objeto. Essa consumação do hibridismo tem como principal resultado a imersão do usuário, que deixa de ser leitor, posicionado do lado de fora da página, para se transformar em participante, posicionado internamente. Tudo isso traz desafios e benefícios para o ensino de línguas: de um lado exige novas competências do professor, mas de outro, acena com a promessa de uma experiência de aprendizagem mais intensa e envolvente para o aluno. 


\section{REFERÊNCIAS}

AHMAD, K.; CORBETT, G.; ROGERS, M.; SUSSEX, R. Computers, language learning and language teaching. Cambridge: Cambridge University Press, 1985.

BAX, S. CALL: past, present and future. System, v. 31, n.1, p. 13-28, 2003.

CHAPELLE, C. A. Computer assisted language learning. In HINKLE, E. (Org.) Handbook of research in second language learning and teaching. Hillsdale, $\mathrm{NJ}$ :

Lawrence Erlbaum Associates, 2005. p. 743-756.

DOUGHTY, C.; WILLIAMS, J. Focus on form in classroom second language acquisition. Cambridge: Cambridge University Press, 1998.

ECO, U. Obra aberta. São Paulo: Perspectiva, 1976.

FOTOS, S; NASSAJI, H. (Orgs.). Form-focused instruction and teacher education. Oxford: University Press, 2007.

GOODMAN, K. S. Unidade na leitura: um modelo psicolinguístico transacional. Letras de Hoje, n. 86, p. 9-43, 1991.

GOOGLE EARTH. Disponível em http://www.google.com.br/intl/ptBR/earth/index.html. Acesso em: 01 ago. 2011.

HALLIDAY, M.A.K. An introduction to Functional Grammar. 2. ed. Londres: Arnold, 1994.

HIGGINS J. Language, learners and computers. London: Longman, 1988.

HIGGINS J.; JOHNS T. Computers in language learning. London: Collins ELT and Addison-Wesley, 1984.

ISER, W. The implied reader: patterns of communication in prose fiction from Bunyan to Beckett. Baltimore and London: John Hopkins University Press, 1974.

KENNING M. M.; KENNING M. J. Computers and language learning: current theory and practice. New York: Ellis Horwood, 1990.

KNOBEL, M.; LANKSHEAR, C. A new literacies sampler. New York: Peter Lang Publishing, Inc., 2007.

KRESS, G. R.; VAN LEEUWEN. Reading images: the grammar of visual design. 2. ed. New York: Routledge, 2006.

LEFFA, V. J.. A aprendizagem de línguas mediada por computador. In:

LEFFA, V. J. (Org.). Pesquisa em Linguística Aplicada: temas e métodos. Pelotas: Educat, 2006. p. 11-36. 
. Interação, mediação e agência na aprendizagem de línguas. In:

BARCELOS, A. M. F. (Org.). Linguística Aplicada: reflexões sobre o ensino e aprendizagem de língua materna e língua estrangeira. Campinas, SP: Pontes Editores, 2011. p. 275-295.

LEMKE, J. L. Travels in hypermodality. Visual Communication, v. 1, n. 3, p. 299325, 2002.

LÉVY, P. Cibercultura. São Paulo: Editora 34, 1999.

LONG, M.; ROBINSON, P. Focus on form: theory, research, and practice. In: DOUGHTY, C.; WILLIAMS, J. Focus on form in classroom second language acquisition. Cambridge: Cambridge University Press, 1998. p. 15-41.

MOORE, M. G. Teoria da distância transacional. Revista Brasileira de Aprendizagem Aberta e a Distancia, São Paulo, Agosto 2002. Publicado originalmente em KEEGAN, D. Theoretical principles of distance education. London: Routledge, 1993. p. 22-38. Traduzido por Wilson Azevêdo, com autorização do autor.

NISHIKADO, T. Space Invaders. Taito. 1975. Disponível em: < http://www.spaceinvaders.de/>. Acesso em: 09 maio 2011.

OLIVEIRA, S. Texto visual e leitura crítica: o dito, o omitido, o sugerido. Linguagem \& Ensino, v. 9, n. 1, p. 15-39, 2006.

PAIVA, V. L. M. O. O uso da tecnologia no ensino de línguas estrangeiras: breve retrospectiva histórica. Belo Horizonte, 2008. Disponível em: <http://www.veramenezes.com/techist.pdf>. Acesso em: 01 dez. 2010. PAPERT, S. Logo: computadores e educação. Tradução de José A. Valente. 3. ed. São Paulo: Brasiliense, 1985.

SALEN, K.; ZIMMERMAN, E. Rules of play: game design fundamentals. Cambridge, MA: MIT Press, 2004.

SMITH, F. Compreendendo a leitura. Porto Alegre: Artes Médicas, 2003.

SWAIN, M. Languaging, agency, and collaboration in advanced second language learning proficiency. In: BYRNES, H. (Org.) Advanced language learning: the contributions of Halliday and Vygotsky.London: Continuum, 2006. p. 95-108.

VAN PATTEN, B. Cognitive aspects of input processing in second language acquisition. In: HASEHMIPOUR, P. ; MALDONADO, R.; VAN

NAERSSEN, M. (Orgs.). Studies in language learning and Spanish linguistics in honor of Tracy D. Terrell. New York: McGraw-Hill, 1995. p. 170-183.

VIDAL, R. T. Ensino-aprendizagem do foco na forma: retorno ou recomeço? The ESPecialist, v. 28, n. 2, p. 159-184, 2007. 
WARSCHAUER, M. Computer-assisted language learning: an introduction. In FOTOS, S. (Org.) Multimedia language teaching. Tokyo: Logos International, 1996. p. 3-20.

WONG, W.; VAN PATTEN, B. The evidence is IN: drills are OUT. Foreign Language Annals, v. 36, n. 3, p. 403-423, 2003.

Recebido em: 08/09/11. Aprovado em: 23/07/12.

Title: Interactive page design from a Social Semiotics perspective

Authors: Vilson José Leffa; Gabriela Q. Marzari

Abstract: The use of computers in language teaching and learning, while providing a more interesting environment for the teacher, has also required a good command of some difficult skills. The aim of this text is to reflect on the digital page as an interactive space that is propitious to learning. For that purpose, we do a retrospective study of the printed page, showing that it has a powerful bearing on the development of the digital page, which leads to the need to make a distinction between the digital page, essentially static, and the interactive digital page, essentially dynamic. While the printed and the digital page have readers, who are positioned outside the page, the interactive page has participants, who are positioned inside, in total immersion. It is assumed that the comprehension and exploration of the affordances provided by the interactive page can bring an important contribution to language teaching, making it more effective.

Keywords: Language learning. CALL. Social semiotics.

Título: Diseño de la página interactiva en la perspectiva de la Semiótica Social Autores: Vilson José Leffa; Gabriela Q. Marzari

Resumen: El uso de los ordenadores en la enseñanza y aprendizaje de lenguas, al mismo tiempo en que puede tornar más interesante el trabajo del profesor, ha también exigido el dominio de nuevos conocimientos ni siempre fáciles de ser adquiridos. El objetivo de este texto es reflexionar sobre la página digital como espacio de interacción propicio al aprendizaje. Para eso, se hace un retrospecto de la página impresa y se muestra que ella tiene un peso muy grande sobre el desarrollo de la página digital, lo que lleva a la necesidad de hacer una distinción entre la página digital, esencialmente estática, y la página digital interactiva, esencialmente dinámica. Mientras la página impresa y la digital tienen lectores, que se posicionan externamente, la página interactiva tiene participantes, que se posicionan internamente, en inmersión total. Se cree que la comprensión y la exploración de los recursos de la página interactiva pueden traer una contribución importante para una enseñanza de lenguas más eficiente.

Palabras-clave: Aprendizaje de lenguas. Aprendizaje mediada por ordenador. Semiótica Social.

Linguagem em (Dis)curso, Tubarão, SC, v. 12, n. 2, p. 495-516, maio/ago. 2012 